\title{
LA JURISPRUDENCIA COMO FUENTE FORMAL DEL DERECHO EN Cuba
}

\author{
Case law as a Formal Source \\ OF LAW IN CuBA
}

\author{
A JURISPRUDÊNCIA COMO FONTE \\ FORMAL DO DIREITO EM CUBA
}

CARLOS JUSTO BRUZÓN VILTRES*

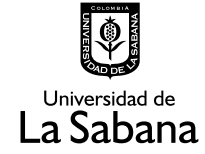

RECIBIDO: 23/O4/2018. ENVÍO A PARES: 25/05/2018 APROBADO POR PARES: 09/07/2018. ACEPTADO: 24/07/2018

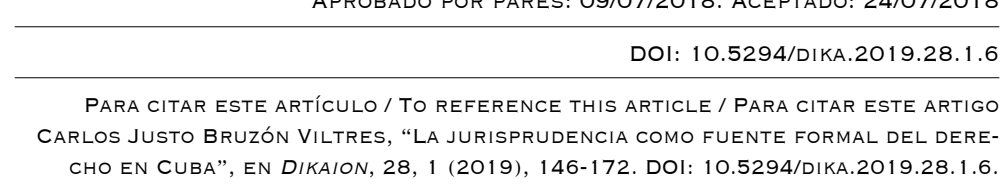




\section{RESUMEN}

La cuestión de las fuentes del derecho es objeto de permanente preocupación en el ámbito de la doctrina jurídica. Dentro de esta, el valor de la jurisprudencia es un tópico polémico, especialmente en el sistema continental y de modo particular en el ordenamiento jurídico cubano. El presente artículo se enfoca en fundamentar el carácter de fuente formal de la jurisprudencia, que implica su obligatoriedad, lo cual contribuiria significativamente a la uniformidad de la actividad judicial y la seguridad jurídica. Para el alcance de este objetivo se formulan ciertas condiciones -denominadas de validez formal-, en el contexto de justificación del derecho interno, en tanto posibles referentes ante las necesarias modificaciones normativas y en sede judicial, que conduzcan al efectivo reconocimiento de la jurisprudencia como fuente. En esta dirección quedan planteados los principales resultados. El análisis se llevó a cabo con los métodos de sintesis, histórico y comparado, así como la consulta de expertos.

\section{PALABRAS CLAVE}

Obligatoriedad de la jurisprudencia; validez formal de las fuentes del derecho; derecho cubano; sistema judicial cubano; Cuba. 


\section{ABSTRACT}

Sources of law are subject to constant consideration in the field of legal doctrine. Within it, the value of case law is controversial, especially in the continental system and particularly in the Cuban legal system. This article focuses on substantiating the formality of case law, including its mandatory nature, which would significantly contribute to the uniformity of judicial activity and legal security. To achieve this objective, certain conditions are listed - called formally valid-, in the context of the justification of domestic law, as possible references for necessary regulatory and court modifications that lead to the effective recognition of case law as a source. Main results are presented in this regard. The analysis was carried out using the synthesis, historical and comparative methods, as well as expert consultation.

\section{KEY WORDS}

Binding precedent; sources of law; Cuban law; judiciar; Cuba. 


\section{RESUMO}

A questão das fontes de direito é objeto de permanente preocupação no âmbito da doutrina jurídica. Dentro dela, o valor da jurisprudência é um tópico polêmico, especialmente no sistema romano-germânico e, de modo particular, no ordenamento jurídico cubano. O presente artigo se concentra em fundamentar o caráter de fonte formal da jurisprudência, que implica sua obrigatoriedade, o que contribuiria significativamente para a uniformidade da atividade judicial e da segurança jurídica. Para alcançar esse objetivo, são formuladas certas condições - denominadas de "validade formal" - no contexto de justificação do direito interno, bem como possíveis referentes diante das necessárias modificações normativas e em sede judicial, que conduzam ao real reconhecimento da jurisprudência como fonte. Nesse sentido, apresentamos os principais resultados. A análise foi realizada com os métodos de sintese, histórico e comparado, e também com consultas a especialistas.

\section{PALAVRAS-CHAVE}

Súmula vinculante; fontes de direito; Lei cubana; judiciar; Cuba. 
SUMARIO: INTRODUCCIÓN. 1. LA JURISPRUDENCIA COMO FUENTE EN EL DERECHO CONTINENTAL Y EL DEBATE EN TORNO A SU VALIDEZ FORMAL. 2. DERECHO CUBANO Y JURISPRUDENCIA: HACIA UN NECESARIO RECONOCIMIENTO NORMATIVO DE ESTA FUENTE. 3. CONCLUSIONES. BiBLIOGRAFÍA.

\section{INTRODUCCIÓN}

Una de las mejores formas de entender la estructura y el funcionamiento de un régimen jurídico es a través del análisis de sus fuentes, ${ }^{1}$ que expresan las contradicciones politicas producidas al interior del sistema en la distribución de ámbitos de poder y decisión sobre aspectos de la vida social. Este tópico ha captado durante décadas el interés doctrinal y práctico, y en la actualidad se ha hecho más complejo por fenómenos como el pluralismo jurídico y el antitradicionalismo, de los cuales deriva una concepción de fuentes que, aplicando la metáfora "hidráulica" de Pérez Luño, ${ }^{2}$ aparecen desbordadas como ríos que van a dar al mar del mundo jurídico, en oposición al legalismo impuesto en el sistema continental. Lo anterior provoca una pugna constante por el reconocimiento oficial de las fuentes, aunque estas tengan en la realidad una expresión concreta. ${ }^{3}$

En ese contexto, el estudio de la jurisprudencia se ha convertido en uno de los grandes temas de la cultura jurídica contemporánea, ${ }^{4}$ de ahí que se considere materia inagotable y sin fondo. ${ }^{5}$ Resulta clave, por ende, el acercamiento a la evolución histórica de esta institución ${ }^{6}$ que hunde raíces en las fuentes romanas, seguida de periodos de expansión en la etapa medieval, la influencia del common law desde el siglo XI, su rechazo durante el proceso codificador decimonónico, el tránsito en las postrimerías del siglo XIX del positivismo legalista al positivismo judicialista, y el desarrollo de las doctrinas realistas hasta la proliferación de emergentes o renovadas teorias en las últimas décadas como la del derecho, jurisprudencia y constitución vivientes, el activismo judicial y el nuevo derecho.

El neoconstitucionalismo, las teorias de la argumentación jurídica, la globalización en el campo jurídico y el afianzamiento de las jurisdicciones constitucionales han

1 Javier Pérez Royo, Las fuentes del Derecho, 5 ed., Madrid, Tecnos, 2012, p. 16.

2 Antonio Enrique Pérez Luño, El desbordamiento de las fuentes del derecho, Sevilla, Real Academia Sevillana de Legislación y Jurisprudencia, 1993, p. 104.

3 Entre las tesis de referencia que asignan a la realidad social y a la práctica jurídica un rol protagónico en la producción e identificación del derecho están: tesis de las fuentes sociales (HART y RAz); la regla de reconocimiento como convención constitutiva (VILAJOSANA); el punto de vista interno (HART) y el antitradicionalismo de fuentes (López Medina).

4 Diego E. López Medina, El Derecho de los jueces, Bogotá, Legis, 2011, p. 134.

5 Ramón López VILAS, La jurisprudencia y su función complementaria del ordenamiento jurídico, Madrid, Civitas, 2002, p. 17.

6 Cfr., inter alia, Félix Calvo Vidal, La jurisprudencia, ¿fuente del Derecho?, Valladolid, Lex Nova, 1992; José Puig Brutau, La jurisprudencia como fuente del Derecho, 2 ed., Barcelona, Bosch, 2006;

Rolando TAMAYO Y SALMORÁn, “Jurisprudencia y formulación judicial del Derecho (Principium)”, en
Isonomía 21 (2004), pp. 193-215; LópeZ VILAS, La jurisprudencia y su función complementaria del ordenamiento jurídico, op. cit., pp. 36 y ss. Desde el estudio del método jurídico, véase Frédéric Zenati, La jurisprudence, Paris, Dalloz-Sirey, 1991. 
coadyuvado en la actualidad a la progresiva centralidad de la jurisprudencia, gracias al rol protagónico reconocido a la función judicial. ${ }^{7}$ Así, dentro del universum ius de la "galaxia jurídica", como calificara Vallet de Goytisolo ${ }^{8}$ al ordenamiento jurídico, es posible descubrir a la jurisprudencia en el proceso de interpretación, aplicación y creación judicial del derecho, en la renovación jurídica permanente, en la labor constructiva de muchas figuras jurídicas, en la concrétisation o concreción determinativa del derecho. ${ }^{9}$

La dinámica de los cambios sociales, la imposibilidad del legislador de prever todas las situaciones susceptibles de tutela jurídica, la quiebra del dogma de la plenitud del ordenamiento, las exigencias de seguridad jurídica y de protección de los derechos e intereses ciudadanos, entre otros factores, condicionan la relevancia del papel de esta fuente jurídica en una época que, no por azar, ha sido denominada como el siglo o la era de los jueces. ${ }^{10}$

Sin embargo, la comprensión del carácter de fuente de la jurisprudencia deviene problemática dada la naturaleza contramayoritaria atribuida al poder judicial para restarle legitimidad a su actividad creativa, así como por las contradicciones doctrinales y la diversidad de formas reconocidas en relación con dicha manifestación jurídica. Ello obliga a adoptar como criterio dominante el de jurisprudencia en sentido estricto, esto es, la que deriva de la actividad de los órganos judiciales superiores en la resolución de casos dificiles, ${ }^{11}$ bajo determinados requisitos de forma y procedimiento.

Los aspectos antes descritos han influido en distintas etapas y formas en el derecho cubano. En la época colonial se produjeron algunos hitos normativos relacionados con el desarrollo jurisprudencial: la implantación de la Real Cédula de 30 de enero de $1855,{ }^{12}$ la Circular de la Audiencia Pretorial de La Habana ${ }^{13}$ ese propio año y en 1866 la Ley de Enjuiciamiento Civil, que contemplaba dentro de las causales de

7 Cfr., Giuseppe ZACCARIA, "La jurisprudencia como fuente de Derecho: una perspectiva hermenéutica”, en Isonomía 32 (2010), pp. 93-117.

8 Apud López VILAS, La jurisprudencia y su función complementaria del ordenamiento jurídico, op. cit., p. 175.

9 Cfr., Puig Brutau, La jurisprudencia como fuente del Derecho, op. cit., p. 135; Ramón López Vilas, La jurisprudencia y su función complementaria del ordenamiento jurídico, op. cit., p. 175; Eric MillaRD, Théorie Générale du Droit, Paris, Dalloz, 2006, pp. 101 y ss.; Juan B. VALLET DE GoYTisolo, "El razonamiento judicial”, en Anales de la Real Academia de Jurisprudencia y Legislación 39 (2009), p. 31.

10 Véase David OrdóñEz Solís, Jueces, Derecho y Política. Los poderes del juez en una sociedad democrática, Pamplona, Aranzadi, 2004, p. 85; Rafael Del ÁGulla, La senda del mal, politica y razón de Estado, Madrid, Taurus, 2000, p. 293.

11 Se entiende por casos dificiles aquellos en los que se producen problemas de relevancia o de interpretación. Siguiendo en esta dirección los criterios posteriormente comentados de autores como DWorkin o ANDALUZ Vegacenteno son problemas de relevancia los supuestos en que no existe norma aplicable al caso (ausencia) y problemas de interpretación los relacionados con el significado y alcance de la norma (insuficiencias), derivados de la propia naturaleza del lenguaje jurídico.

12 Que establecía en el artículo 183 la obligación de los jueces de fundamentar todas sus resoluciones.

13 Circular de la Audiencia Pretorial de La Habana de 26 de abril de 1855, complementaria de la anterior disposición, que indicaba encontrar el fundamento del fallo, entre otros criterios, en "las resoluciones dadas por los tribunales superiores". 
casación la infracción de doctrina legal, figura que fue posteriormente equiparada con la jurisprudencia. ${ }^{14}$

La existencia desde 1899 del Tribunal Supremo y las transformaciones operadas en la organización judicial a inicios del siglo XX fueron factores esenciales en la acentuación del debate jurisprudencial cubano. La vehemente defensa que sobre la jurisprudencia como fuente hiciera José A. del Cueto ${ }^{15}$ en 1918, y los aportes doctrinales realizados por destacados juristas de entonces representan ejemplos de la intensidad con que este tema fue abordado durante aquella etapa. ${ }^{16}$

Las transformaciones institucionales derivadas del triunfo revolucionario de 1959 impactaron en la estructura y el funcionamiento de los tribunales. Concluidos los informes encargados a las Comisiones de Estudios Jurídicos, a finales de la década de los sesenta, ${ }^{17}$ era un hecho el abandono del denominado sistema de jurisprudencia. La decisión fue materializada normativamente con la promulgación de las leyes 1250 de Organización del Sistema Judicial, en 1973 y la 1261 de 4 de enero de 1974, de Procedimiento Civil y Administrativo; con esta última disposición se eliminó la infracción de doctrina legal como causal del recurso de casación y, con ello, la posible referencia a la jurisprudencia por esta vía.

En los años posteriores se agudizó el rechazo de la jurisprudencia bajo condicionamientos esencialmente políticos ${ }^{18} \mathrm{y}$ de retorno al legalismo preconizado por la doctrina jurídica del extinto campo socialista, ${ }^{19}$ como muestran parte de los textos jurídicos escritos en la época ${ }^{20}$; esta tendencia al "copismo" ignoró, incluso, algunos cambios que relativizaron el legalismo predominante en la teoría de las fuentes y aceptaron la utilidad de la jurisprudencia también en el derecho socialista. ${ }^{21}$

14 El propio Tribunal Supremo cubano lo reconoció en varias de sus sentencias (v. gr., sentencias 2 de 18 de marzo de 1908; 122 de 15 de septiembre de 1926; 9 de 30 de enero de 1933, inter alia).

15 José A. Del Cueto, Discurso leído en la solemne apertura de los tribunales el 2 de septiembre de 1918, La Habana, Librería e Imprenta “La Moderna Poesía”, 1918.

16 En una larga lista de autores se incluyen Aramburo, Fernández Camus, De Montagú, Entenza Escobar, Sánchez de Bustamante y Montoro, Sánchez de Bustamante y Sirvén, Garcerán de Vall, Álvarez Tabio.

17 Véase Explicación IV, inciso c), de las Bases sobre unificación de las jurisdicciones. Principios y estructura del nuevo sistema judicial, en: Comisiones de Estudios Jurídicos. Secretariado, ¿Cómo debemos organizar el nuevo sistema judicial?, La Habana, 1971, p. 10.

18 En el acto de investidura de los nuevos jueces del Tribunal Supremo Popular y de los tribunales provinciales en el año 1973, Blas Roca CALDERío afirmó que "en este sistema, el viejo método de la llamada jurisprudencia se desecha”. Los oradores que le antecedieron, incluido Enrique HART RAMíREz, presidente del máximo órgano judicial, omitieron cualquier referencia a este tópico. Era un signo claro de la postura político-institucional de rechazo al carácter de fuente de la jurisprudencia en Cuba. Cfr. AA.VV., "Investidura de los jueces del Tribunal Supremo Popular y de los tribunales provinciales", en Revista cubana de derecho 21 (2013) pp. 83-113.

19 Cfr. O. Zhidkov, V. Chirkin y Y. Yudin, Fundamentos de la teoría socialista del estado y el derecho, Moscú, Editorial Progreso, 1980, p. 334; A. Mánov et al., Teoría marxista del Estado y del derecho, Ciudad de La Habana, Editorial de Ciencias Sociales, 1981, p. 580; Nikolái Máleın, La legislación civil y la defensa de los derechos personales en la URSS, Moscú, Editorial Progreso, 1985, p. 238.

20 Cfr., v. gr., Fernando D. Cañizares, Teoría del Estado, La Habana, Editorial Pueblo y Educación, 1979, p. 80; Héctor Garcini GuerRa, Derecho administrativo, La Habana, Editorial Pueblo y Educa-

152 1979, p. 80; Héctor GARCINI GUERRA, Derecho administrativo, La Habana, Editorial Pueblo y Educa-
ción, 1986, p. 80.
21 Cfr. Hubert IzDEBSKI, "Les sources du droit dans les pays socialistes européens (histoire, théorie, pratique)”, en Revue Internationale de Droit Comparé 38 (1986), p. 21 y ss.; René David y C. 
A partir de los años noventa, la visión sobre la función judicial, desde un prisma garantista, comenzó a transformarse de modo positivo. ${ }^{22}$ La siguiente década resultó fundamental en este cambio de perspectiva con el desarrollo en varias tesis doctorales de temáticas vinculadas a la interpretación y el control constitucional, el rol de la regla de reconocimiento en el ordenamiento jurídico, el papel del juez en la integración del derecho y la relevancia del estudio de las fuentes, incluida su dimensión plural. ${ }^{23}$ En parte de estas obras fue ponderado el reconocimiento de la función judicial en los procesos de interpretación, aplicación y creación del derecho. Contribuyen al estado actual del tema tratado tesis de maestría y de especialidad elaboradas desde la actividad judicial, ${ }^{24}$ junto a otras contribuciones teóricas referenciadas en la bibliografía utilizada. ${ }^{25}$ La mayoria de estos estudios se concentran en una rama o disciplina jurídica específica, sin que por ello dejen de realizar útiles aportaciones teóricas.

JAUfFret-Spinosi, Los grandes sistemas jurídicos contemporáneos (trad. de J. SÁnchEZ CoRdero), México, UNAM-Centro Mexicano de Derecho Uniforme-Facultad Libre de Derecho de Monterrey, 2010, pp. 152 y ss. Sin renunciar al papel central de la ley, JAwiTsch advertía que las formas jurídicas no debían reducirse a aquella y que en su formación las fuerzas sociales tenían un peso considerable. Cfr. L. S. JAwitsch, Teoria general del derecho, La Habana, Ciencias Sociales, 1988, pp. 103-105, 256 y ss.

22 Al respecto, véanse los artículos publicados por autores cubanos en la revista colombiana El otro derecho, en el año 1994 y, por su importancia, Danelia CuTí́ Mustelier, "El sistema de garantías de los derechos humanos en Cuba”. Tesis en opción al grado científico de Doctor en Ciencias Jurídicas, Universidad de Oriente, Santiago de Cuba, 1999, especialmente en lo atinente al subsistema de garantías jurisdiccionales.

23 Algunas de las tesis doctorales revisadas fueron: Ángel Mariño CASTEllanos, "El control constitucional en Cuba" (Universidad de Oriente, Santiago de Cuba, 1995); Martha PRIETo ValdÉs, "El Derecho, la Constitución y su interpretación" (Universidad de La Habana, 2002); Walter Mondelo GarCíA, "El orden jurídico, la Constitución y la regla de reconocimiento" (Universidad de Oriente, Santiago de Cuba, 2003); Karel РАснот ZAMBRANA, "El derecho al deporte, la Constitución y las normas de ordenación del deporte en Cuba” (Universidad de Oriente, Santiago de Cuba, 2007); Majela FERRARI YAunNER, "Los principios de legalidad y seguridad jurídica como fundamentos del proceso de integración del Derecho para colmar las lagunas de la ley en Cuba” (Universidad de La Habana, 2010); Juan R. PéREZ CARrillo, "Presupuestos teóricos para el reconocimiento normativo de las fuentes formales legisladas del Derecho Agrario en Cuba” (Universidad de Oriente, Santiago de Cuba, 2013). Igualmente, un proyecto de investigación doctoral (no concluido): Rafael E. DUJARRIC HART, "La jurisprudencia en el sistema de fuentes del Derecho Civil en Cuba" (Universidad de La Habana, 2008). La mayoría de estas investigaciones pueden encontrarse en el repositorio de tesis doctorales cubanas de la Red Nacional Universitaria (disponible en: www.reduniv.edu.cu) o en la Secretaría del Tribunal de Grado para las Ciencias Jurídicas, en la Universidad de La Habana, de la cual se han obtenido en formato digital las tesis referenciadas (consultadas por el autor desde 2013 a la fecha).

24 Bárbara SÁnchez Rodríguez, "La jurisprudencia: ¿método de interpretación o de creación en el Derecho Penal?” Tesis en opción al título de Especialista en Derecho Penal, Santiago de Cuba, 2007; Raisa M. Aguirre Alonso, "La jurisprudencia como fuente del Derecho en Cuba. Una mirada desde la actuación de las salas de lo Civil y de lo Administrativo". Tesis en opción al título académico de Máster en Derecho Constitucional y Administrativo, La Habana, 2013; Cenia González MenÉndez, "La jurisprudencia como fuente formal del Derecho Penal cubano. Su utilidad práctica". Tesis en opción al título de Especialista en Derecho Penal, Sancti Spíritus, 2014.

25 Cfr. inter alia, Julio Fernández Bulté, Teoría del Estado y del derecho, t. 2, La Habana, Editorial Félix Varela, 2004, pp. 51-96; Andry Matilla Correa, “Comentarios sobre las fuentes del derecho administrativo cubano (excepto el reglamento)", en Armando Castanedo ABay et al., Temas de derecho administrativo cubano, La Habana, Editorial Félix Varela, 33-219, 2006, pp. 89 y ss.; Ciro Félix Rodríguez Sánchez y R. M. Hernández, "La jurisprudencia como fuente complementaria del Derecho”, en AA. VV., Memorias de la IV Conferencia Científica sobre el Derecho, Santiago de Cuba, Universidad de Oriente, 1997, pp. 39-44. 
Estos elementos hacen pertinente el tema analizado, en tanto el tratamiento de la jurisprudencia desde de la teoría general de las fuentes y el ámbito específico de su validez formal, con una perspectiva que irradia a todo el ordenamiento jurídico, incorpora elementos de novedad en un escenario doctrinal en el cual este tipo de estudios son poco frecuentes.

Una de las problemáticas más significativas que enfrenta la jurisprudencia como fuente está relacionada precisamente con la validez formal, de ahí que la principal contradicción que se produce en torno a la institución analizada radica en el reconocimiento fáctico frente a su omisión normativa. Empero, al ser el reconocimiento normativo de esta fuente una cuestión controversial matizada por criterios políticos, aquel debe estar sujeto a determinadas condiciones que permitan convertirla en un medio del cual el juez pueda hacer uso para fundamentar jurídicamente su actuar, es decir, en una verdadera fuente formal. ${ }^{26}$

\section{LA JURISPRUDENCIA COMO FUENTE EN EL DERECHO CONTINENTAL Y EL DEBATE EN TORNO A SU VALIDEZ FORMAL}

La postura antitradicionalista presupone la oposición al discurso tradicional sobre las fuentes, prevaleciente durante más de dos siglos en el derecho continental. ${ }^{27} \mathrm{El}$ tradicionalismo de fuentes afecta directamente a la función judicial y a la interpretación y el uso en la dimensión práctica o empírica de las fuentes como medios para la solución de casos. ${ }^{28}$

26 Cfr. Juan Mendoza Díaz et al., Lecciones de derecho procesal civil, La Habana, Editorial Félix Varela, 2001, p. 9.

27 Es oportuno recordar que las tendencias antitradicionalistas tienen importantes antecedentes históricos. Contra el tradicionalismo expresado en los presupuestos de la exégesis francesa, método que Gény no por azar denominó "tradicional”, se alzaron la escuela histórica alemana (Hugo, Puchta y Savigny), los defensores de la concepción finalista del derecho expuesta por von Ihering y nucleados en torno a la llamada jurisprudencia de intereses, así como la escuela del derecho libre (Bülow, Ehrlich y Kantorowicz). La obra de Gény y la escuela científica francesa constituyeron los mejores ejemplos de oposición radical y definitiva frente a aquella corriente. Luego sobrevino el enfrentamiento que al iniciarse el siglo XX adquirió el título de revuelta antiformalista, a la que tributaron significativamente el realismo jurídico y la jurisprudencia sociológica, por solo citar dos ejemplos. Cfr. Puig Brutau, La jurisprudencia como fuente del Derecho, op. cit., pp. 99 y ss.; LóPEZ VILAS, La jurisprudencia y su función complementaria del ordenamiento jurídico, op. cit., pp. 65 y ss.; Calvo Vidal, La jurisprudencia, op. cit., pp. 103 y ss.; PÉrez Luño, El desbordamiento de las fuentes del Derecho, op. cit., p. 90; François GÉNY, Método de interpretación y fuentes en Derecho Privado positivo, Madrid, Reus, 1925, p. 194.

28 Implica, además, por su propio efecto, el reconocimiento de un número más amplio de fuentes, que se convierten en medios para la acción y decisión del operador, en especial el juez. Dentro de ese catálogo de fuentes formales, además de la Constitución y la ley, entran en escena la costumbre, los principios generales del derecho, los tratados internacionales, contratos, convenios colectivos de trabajo, etc. Atención particular merece la doctrina, cuyo carácter de fuente formal ha sido arduamente discutido en el ámbito jurídico contemporáneo, sin acuerdos totales al respecto. Pero ciertamente, en la formulación jurisprudencial del derecho el fundamento doctrinal tiene un peso decisivo, pues el juez no siempre puede desentrañar el alcance de la ley $\mathrm{u}$ otra fuente y construir su argumento decisional con el precepto exclusivamente. Las interpretaciones doctrinales sobre una norma o institución aportan y sirven (al operar como fuente subyacente) para fijar criterios 
Esta caracterización reduce el papel del juez a mero aplicador de la ley, que debe obediencia a una regla clara o evidente prescrita por el legislador y es independiente frente al resto de las sentencias dictadas con anterioridad, lo que convierte a la jurisprudencia en una fuente secundaria o auxiliar que opera solo en casos de silencio de la fuente primaria. ${ }^{29}$

La critica al método tradicional aparece sustentada entonces en tres inconsistencias básicas del paradigma anterior: i) la incapacidad de este modelo de lidiar con los problemas relativos al sistema de fuentes al pretender preordenar desde la ley de manera exhaustiva el comportamiento argumentativo de los operadores jurídicos; ii) la incorrección sustancial de su habitualmente aceptada jerarquización de las fuentes del derecho en la forma de pirámide normativa y, iii) la pretensión de ignorar que el problema de las fuentes tiene un componente politico fundamental. ${ }^{30}$ Dentro de las tesis que asumen una postura antitradicionalista pueden mencionarse la del "pastel de fuentes" o enfoque de circularidad de González Jácome, ${ }^{31}$ y la mezcla o combinación de las fuentes en el razonamiento judicial, de Bernal Cano $^{32}$; son útiles además en la evaluación de la cuestión de las fuentes desde una perspectiva pluralista algunos argumentos implícitos en las tesis de las fuentes sociales $\left(\mathrm{Hart}^{33}, \mathrm{Raz}^{34}\right.$ ) y la regla de reconocimiento como convención constitutiva (Vilajosana ${ }^{35}$ ), las cuales no están reñidas por su fundamento esencialmente práctico con la necesaria propuesta de reconocimiento oficial de dichas fuentes, en respuesta a las exigencias de la seguridad juridica y la institucionalidad estatal. Es posible afirmar que el antitradicionalismo constituye un buen punto de partida para comprender la complejidad del fenómeno de las fuentes del derecho en un contexto matizado por el pluralismo jurídico, ${ }^{36}$ en el cual el esquema legalista deja

jurisprudenciales. No en vano se ha ponderado en determinas épocas y ordenamientos el rol de la doctrina legal (de base esencialmente interpretativa) o la doctrina probable (como es el interesante caso colombiano, desde la promulgación de la Ley 169 de 1896). No es casual tampoco que la jurisprudencia haya sido "confundida" entre estas y otras figuras análogas, que tienen en el valor teórico-práctico de la doctrina su pilar fundamental.

29 López Medina, El derecho de los jueces, op. cit., pp. 3-4; "Tres caminos históricos en la formación de la jurisprudencia en América Latina: recepción y vicisitudes del concepto de 'doctrina legal' en la región”, en A. GonZÁlez y J. Del Río (comps.), Discusión jurídica contemporánea desde Michoacán, México, Tribunal Electoral del Estado de Michoacán, 1-32, 2011, p. 2. En este escenario también la enseñanza del derecho se limita al derecho legislado, y es escasamente conocido el derecho de origen judicial, el que además es de difícil acceso y está pobremente ordenado y sistematizado.

30 López Medina, El derecho de los jueces, op. cit., pp. 268-269.

31 Jorge GonZÁlez JÁcome, "El problema de las fuentes del derecho: una perspectiva desde la argumentación jurídica”, en Vniversitas 112 (2006), pp. 265-293.

32 Natalia Bernal CANo, "El poder creador del juez en la combinación o mezcla de los procedimientos constitucionales", en Estudios socio-jurídicos 12 (2010), p. 15.

33 Herbert L. A. HART, Post scriptum al concepto del derecho, México, UNAM, trad. de Rolando TAMAYO y SALMORÁn, 2000, p. 51.

34 Joseph RAz, El concepto de sistema jurídico. Una introducción a la teoría del sistema jurídico, UNAM, México, trad. de Rolando TAMAYO y SALMORÁn, 1986, p. 255; La autoridad del derecho. Ensayos sobre derecho y moral, México, UNAM, trad. de Rolando TAmayo y SALmorán, 1985, pp. 55 y ss.

35 Josep M. Vilajosana, Identificación y justificación del derecho, Madrid, Marcial Pons, 2007, p. 60.

36 El pluralismo jurídico, como afirma el profesor Garzón López, es un concepto complejo y polisémico, que básicamente hace referencia a "una perspectiva que cuestiona aquella concepción monista que ha reducido la diversidad endémica de la sociedad a una sola visión dominante del derecho". Este concepto tiene un carácter multidimensional motivado por la concurrencia de una “constelación" de legalidades e ilegalidades -afirma el autor, siguiendo a De Sousa- impuesta por 
de ser la opción argumentativa más idónea. Es necesario un cambio de paradigma respecto a la lectura de las fuentes, con un enfoque de circularidad que permita al operador jurídico y al juez en particular descubrir en las fuentes medios complementarios, no excluyentes, para sustentar su razonamiento y decisión.

En relación con la evolución histórica y conceptual de la jurisprudencia, este ha sido un proceso complejo caracterizado por confrontaciones teóricas, bajo la influencia de circunstancias objetivas en las que han dejado su impronta los factores políticos y jurídicos, en el que se identifican las siguientes etapas:

- Formación del concepto de jurisprudencia, mediado por el carácter ambiguo en la utilización del término, cuyo punto de referencia es el derecho romano $\mathrm{y}$ sus fuentes.

- Expansión de la creación judicial del derecho durante la época medieval, matizada por el rescate e intento de sistematización de las fuentes romanas, la influencia de los tribunales al servicio del régimen monárquico y las instituciones jurídicas del common law, en particular el precedente judicial.

- Influencia de la jurisprudencia durante la modernidad europea y en la actividad de las reales audiencias al aplicar el denominado "derecho indiano", en la América colonizada.

- Rechazo formal a la creación judicial del derecho y al reconocimiento normativo de la jurisprudencia como fuente a partir del proceso codificador del siglo XIX; aunque a pesar de ello se desarrollaron instituciones como la jurisprudencia constante y la doctrina legal.

- Recepción de las teorías principalmente de corte anglosajón que ponderaban el papel de la función judicial en la formación del derecho durante la primera mitad del siglo XX.

- Amplificación del valor de la jurisprudencia como fuente a partir de la proliferación de las jurisdicciones constitucionales y la globalización jurídica. ${ }^{37}$

grupos o sectores, que establecen normatividades particulares, en franca disputa por el monopolio estatal de lo jurídico. El uso del término en este estudio tiene una estrecha relación con lo que el profesor Correas ha denominado "pluralismo de fuentes o de aplicadores del derecho", que encaja perfectamente con la visión antitradicionalista desmarcada del rol absoluto y excluyente de la ley en el ordenamiento interno. Cfr. Pedro Garzón López, "Pluralismo jurídico", en Eunomia. Revista en cultura de la legalidad 5 (2013-2014), pp. 186-193; Oscar CoRrEAs, Teoría del derecho, México, Fontamara, 2004, pp. 168 y ss.

37 En cuanto a la globalización jurídica, en el presente trabajo debe considerarse la idea sostenida por el tratadista Paolo Grossi, al calificar este fenómeno en tanto "realidad concreta e innovadora que obliga a profundas revisiones de la dogmática tradicional, al tratarse de una forma de pluralismo jurídico", que tiene expresiones singulares en la emergencia de una especie de "jurisprudencia global" (Slaughter) o "mundialización de las prácticas judiciales globales" (Mattei). Así, la labor de ciertos órganos jurisdiccionales (tal es el caso de las cortes supranacionales europeas y, en nuestra región, la Corte Interamericana de Derecho Humanos) implica la observancia de criterios jurisprudenciales al interior de los Estados (mediante doctrinas de amplia aceptación, como la del control de convencionalidad, cuyo análisis desbordaría el alcance de este artículo); este constituye un efecto inocultable de la circulación de prácticas jurídicas y modelos, propios de un mundo que interactúa constantemente, en el que se produce una suerte de "ubicuidad judicial" (Ferrarese). 
En la actualidad, la jurisprudencia ha adquirido caracteres de progresiva centralidad en el contexto continental, influida por doctrinas como el derecho, el constitucionalismo y la jurisprudencia vivientes, el activismo judicial, el neoconstitucionalismo y, en el ámbito latinoamericano específicamente, el llamado nuevo constitucionalismo latinoamericano, el nuevo derecho y las teorias de la argumentación jurídica.

Como signo común, estas teorías exaltan el papel de la función judicial en el proceso de interpretación, aplicación y creación del derecho, acorde con la dinámica de cambio social a la cual debe dar respuesta el juez con mayor grado de libertad.

La tendencia actual es circunscribir la jurisprudencia exclusivamente a la producción de los órganos jurisdiccionales del Estado y, de modo más estrecho, únicamente a las resoluciones de los tribunales supremos. ${ }^{38}$ Por otra parte, al considerar los criterios de expertos internacionales consultados y la regulación particular de esta fuente en distintos ordenamientos jurídicos (España, México, Colombia, Ecuador, Venezuela, Bolivia, Brasil), ha sido posible sistematizar varias manifestaciones de jurisprudencia como fuente del derecho continental:

- La solución contenida en la ratio decidendi de sentencias dictadas en salas de los tribunales superiores, con tendencia a la reiteración y carácter obligatorio ante la ausencia o insuficiencia de una norma aplicable al caso.

- La reiteración de fallos fundados emitidos por los órganos superiores de justicia en la resolución de asuntos de similar naturaleza.

- Las sentencias emanadas de tribunales o salas especializadas en materia constitucional, que conforman la jurisprudencia o precedentes constitucionales obligatorios. $^{39}$

- Las resoluciones judiciales adoptadas en procedimientos jurisdiccionales específicos que, tras un proceso acumulativo, conllevan la formación jurisprudencial, por ejemplo, en materia de amparo, electoral, agraria, ambiental, etc.

- Las resoluciones judiciales que resuelven recursos de casación y contemplan extremos novedosos en la solución jurídica aportada.

Cfr. Paolo Grossi, De la codificación a la globalización del derecho, Navarra, Aranzadi-Thomson Reuters, 2010, p. 237.

38 Ítalo LudER, "Concepto, función y técnica de la jurisprudencia”, en Revista jurídica argentina La Ley 37 (1945), p. 901. Según el destacado procesalista italiano Michele Taruffo "se comprueba la existencia de una tendencia constante a identificar a las cortes supremas como los órganos a los que se confia la tarea de asegurar la unidad de la jurisprudencia". Véase Michele TARUfFo, "La jurisprudencia entre casuística y uniformidad”, en Revista de derecho (Valdivia) XXVII (2014), p. 13.

39 De lo cual es preciso insistir -amén de sus lógicas distinciones conceptuales y funcionales- en el carácter vinculante de su jurisprudencia en un tenor similar al que se explica en este artículo respecto a la jurisprudencia fijada en sede de los tribunales o las cortes supremas. Se produce una necesaria equiparación en materia de efectos de cara a la formación de la jurisprudencia como fuente formal. 
- Diferentes modalidades de la interpretación jurisprudencial como la extensiva, evolutiva o sociológica, progresiva, integrativa o con propósito de enmienda.

De este catálogo resulta necesario precisar que la forma técnicamente más adecuada de identificar la jurisprudencia es la reiteración de los fundamentos de la decisión contenida en las sentencias (ratio decidendi) que resuelve extremos no establecidos o insuficientemente regulados en la norma.

El análisis precedente conecta con otro tópico fundamental: la determinación del carácter atribuido a la jurisprudencia, es decir, si se trata de una fuente formal, material, directa o indirecta, u otra tipologia que descriptivamente coadyuve a su correcta identificación dentro del sistema de fuentes, lo que implica un juicio de validez de dicha fuente, signado en la actualidad por una mayor problematización y sofisticación. ${ }^{40}$

Este hecho representa el punto de partida para el estudio de la validez formal. Wróblewski ${ }^{41}$ habla con este propósito de tres conceptos implícitos: los de validez sistémica, factual y axiológica. El primero denota que una norma -y en sentido amplio, una fuente del derecho ${ }^{42}$ - es válida si cumple con determinadas condiciones: i) ha sido promulgada de acuerdo con normas válidas en el sistema de referencia, o sea, ha entrado en vigor; ii) es una consecuencia reconocida de las normas válidas; iii) no ha sido formalmente rechazada o derogada; iv) no es inconsistente con el resto de las normas válidas del sistema. ${ }^{43}$ La validez factual deviene de la aplicabilidad operativa de la norma o fuente, de su uso en la resolución de casos. La validez axiológica se predica de la coherencia con elementos valorativos en el sistema, lo que significa aceptabilidad social de la norma o fuente en cuestión; en tanto la

40 Patricia Cuenca Gómez, "Sobre la complejidad de la teoría jurídica de la validez en Principia iuris". Conferencia dictada en el Primer Encuentro de Jóvenes Investigadores de la Sociedad Española de Filosofía Jurídica y Política: "Neoconstitucionalismo en tiempos de postdemocracia", Universitat de València, 25 de abril 2012, p. 2.

41 Cfr. J. Wróblewski, The Judicial Application of Law, Dordrecht, Springer-Science+Business MediaBV, 1992, pp. 75 y ss.; "Validitá e struttura del sistema giuridico. Metateoria e teoria pura del diritto”, en Letizia Gianformaggio (comp.), Sistemi normativi statici e dinamici, analisi di una tipología kelseniana, Turín, Giappichelli, 1991. Véase, además, Victoria IturRalde SEsma, "Reflexiones sobre los conceptos de validez y existencia de las normas jurídicas”, en Doxa. Cuadernos de Filosofia del Derecho 31 (2008), pp. 158-159.

42 La orientación del término validez normativa hacia el de validez de las fuentes o validez jurídica en general no resulta arbitraria. Existe una conexión muy estrecha entre estas categorias, según exponen Atienza y Ruiz Manero, siguiendo a Aguiló Regla. Estos autores afirman que se predica la validez de un grupo de normas (las que confieren poder de forma ilimitada -leyes, reglamentos-; de forma limitada -contratos, fallos judiciales-, o las puramente constitutivas -v. gr., costumbres-), por lo que son consecuentemente diversos los resultados institucionales que pueden considerarse válidos o inválidos, los cuales descriptivamente aluden a las fuentes jurídicas. Cfr. Manuel AtienzA y Juan Ruiz MANERo, "Seis acotaciones preliminares para una teoría de la validez jurídica”, en Doxa. Cuadernos de filosofia del derecho 23 (2003), pp. 721-723.

43 Aarnio también sigue este criterio. Cfr. Aulius AArnio, Essays on the Doctrinal Study of Law, Dordrecht, Springer-Science+Business Media-BV, 2011, p. 126. Sobre la última condición descrita, el autor del presente artículo es consciente del carácter de desiderátum jurídico que comporta y la imposibilidad de lograr que el ordenamiento esté presidido por una total armonía, que desplace, de suyo, la existencia de antinomias, lo cual es altamente cuestionable. Pero en perspectiva de aspiración, inclusive, se ha considerado necesario hacer referencia a este elemento implícito en la construcción teórica de la validez sistémica. 
validez sistémica confirma el peso de los elementos de forma y procedimiento en la producción de las fuentes.

De tal manera, la validez formal implicaría el cumplimiento de una serie de requisitos relativos a las formas y los procedimientos para la producción de resultados institucionales. ${ }^{44}$ Estas condiciones estarian asociadas a: i) la emisión por un órgano competente; ii) conforme al procedimiento establecido; iii) conforme lo permitido respecto a su contenido. ${ }^{45}$ En otras palabras, son válidas las normas $\mathrm{y}$ fuentes en cuya producción intervienen funcionarios $\mathrm{u}$ órganos autorizados, que siguen el proceder previsto y que contienen disposiciones no contradictorias respecto a las normas superiores. ${ }^{46}$

La atención puesta sobre la validez formal no debe interpretarse como un contrasentido respecto al posicionamiento antitradicionalista asumido aquí, ni a la invocación de las tesis de las fuentes sociales o de la regla de reconocimiento como convención constitutiva en las cuales la dimensión sociológica y fáctica de la validez adquieren pleno desarrollo. ${ }^{47}$

De lo que se trata es de vincular la validez formal al respeto por las formas, por los procedimientos que permiten identificar adecuadamente el derecho a través de su estructura formal, por lo que se puede aseverar que la jurisprudencia existe y es válida desde el punto de vista fáctico ${ }^{48}$ pero que requiere ser reconocida explícitamente en el ordenamiento jurídico en razón de su correcta identificación, obligatoriedad y en respuesta a las exigencias de seguridad jurídica. ${ }^{49}$

44 Ángeles Ródenas Calatayud, "Validez formal y validez sustantiva. El encaje de la competencia material”, en Doxa. Cuadernos de filosofia del derecho 30 (2007), p. 544.

45 Cfr. Gustavo De Silva GutiérRez, "La norma válida. Análisis sobre la validez de las normas jurídicas”, en Revista de la Facultad de Derecho de México LIX (252) (2009), p. 125. En una perspectiva ampliada, véase Carla Huerta OchoA, Conflictos normativos, México, UNAM, 2003, capítulo cuarto, epígrafe IV; "Fuentes, validez y aplicabilidad de las normas", en E. CÁceres, I. Flores, J. SALdAÑa y E. Villanueva (coords.), Problemas contemporáneos de la filosofia del derecho, México, UNAM, 2005, pp. 303-328.

46 Oscar CoRREAs, Teoría del derecho, op. cit., pp. 88-89. El autor prefiere hablar de proceso de validación de normas en lugar de validez formal.

47 El propio HART respondió afirmativamente ante la pregunta de si la tesis de las fuentes sociales era compatible con la propuesta de normas de reconocimiento que instituían condiciones de validez meta-jurídicas. Cfr. Pilar ZAMBrano, "El rechazo del formalismo y las tesis de las fuentes sociales", pp. 8-9, en bibliohistorico.juridicas.unam.mx/libros/6/2690/5.pdf, fecha de consulta: 23 de abril de 2016

48 Es importante distinguir entre validez fáctica o factual y validez material, términos generalmente empleados de forma indistinta pero que tienen sus especificidades. Así, la validez material o sustantiva se dirige a determinar la compatibilidad entre el contenido de las disposiciones con normas superiores, no es puramente aplicabilidad o uso práctico de la norma o fuente en cuestión. Cfr. Ángeles Ródenas Calatayud, "Validez formal y validez sustantiva. El encaje de la competencia material”, op. cit., p. 544.

49 Véase Antonio Enrique Pérez Luño, "Seguridad jurídica y sistema cautelar", en Doxa. Cuadernos de filosofia del derecho 7 (1990), pp. 327-341; G. Moliner TAMBorero, "Las garantías de seguridad jurídica en las sentencias de casación”, en Actualidad jurídica 35 (2013), pp. 7-24; Luiz G. MARINON, "El precedente en la dimensión de la seguridad jurídica", en Ius et Praxis 18 (2012), pp. 249-266; G. M. Díaz GonZÁlez, "Las oscilaciones del Tribunal Constitucional en su doctrina sobre el principio de seguridad jurídica”, en Revista general de derecho administrativo 32 (2013), pp. 1-34. 
La jurisprudencia es, consecuentemente, fuente formal en tanto deriva de un procedimiento seguido por órganos facultados para la producción jurídica -en este supuesto específico por la regla de adjudicación-, sujeto a determinadas condiciones establecidas por el propio ordenamiento jurídico.

Dentro de los criterios condicionales de la validez jurídica de la jurisprudencia contrastados a partir del análisis de los argumentos doctrinales expuestos, ordenamientos jurídicos comparados y opiniones de expertos ${ }^{50}$ se destacan: el rol de los tribunales o las cortes supremas -incluidos los tribunales constitucionalesen la formación de la jurisprudencia; la identificación de la jurisprudencia a partir de la ratio decidendi de las sentencias pronunciadas en aquellas instancias en la resolución de casos no previstos o insuficientemente regulados en la norma; el requerimiento de publicidad de las decisiones jurisprudenciales; la existencia de mecanismos de disciplina jurisprudencial; el efecto vinculante de esta fuente condicionado por la posibilidad de cambio jurisprudencial y su reconocimiento normativo explicito, preferiblemente en el texto constitucional.

\section{DERECHO CUBANO Y JURISPRUDENCIA: HACIA UN NECESARIO RECONOCIMIENTO NORMATIVO DE ESTA FUENTE}

La caracterización de las líneas generales del debate cubano sobre la jurisprudencia, y la propuesta de condiciones de forma y procedimiento para el reconocimiento de dicha fuente en el derecho interno, constituyen los propósitos fundamentales de este apartado. El análisis desarrollado comprende, además, la revisión de criterios doctrinales sobre el problema general de las fuentes y un examen desde el punto de vista interno de posiciones asumidas en la función judicial respecto a la jurisprudencia en particular.

En materia de discusión doctrinal sobre las fuentes del derecho en Cuba se estableció una periodización relacionada con la vigencia del Código Civil español implantado en Cuba desde el siglo XIX. La influencia de aquella disposición marcó una pauta singular en materia de regulación de las fuentes que fue prontamente recibida en la doctrina y la práctica jurídica cubana al reconocer la validez jurídica de la costumbre y los principios generales del derecho que, a falta de ley, podían ser utilizados en la resolución de casos por los tribunales; formulación sobre la que emergieron las más diversas especulaciones doctrinales e interpretaciones en el ejercicio práctico, especialmente durante la primera mitad del siglo XX.

$50 \mathrm{El}$ artículo, que forma parte de un proyecto de investigación más amplio, consideró las opiniones de una selección de prestigiosos profesores latinoamericanos y europeos, entre ellos: Eric Millard (Universidad Paris X, Nanterre), Diego E. López Medina (Universidad de Los Andes, Colombia) Ernesto J. Vidal Gil (Universidad de Valencia), Nuria Belloso Martín (Universidad de Burgos, España); Josep María Vilajosana (Universitat Pompeu Fabra, Barcelona), Carlos Vidal Prado (UNED, Madrid), Juan Vega Gómez (UNAM, México), Patricio Alejandro Maraniello (Asociación Argentina de Justicia Constitucional). De igual modo, varios de los académicos cubanos cuyas tesis doctorales han sido citadas a lo largo de esta contribución. 
En una larga lista de autores es menester destacar en esta etapa los aportes de Tejera, ${ }^{51}$ Desvernine y Galdós, ${ }^{52}$ Aramburo, ${ }^{53}$ Sánchez de Bustamante y Montoro, ${ }^{54}$ Sánchez de Bustamante y Sirvén, ${ }^{55}$ De Montagú, ${ }^{56}$ Fernández Camus, ${ }^{57}$ Entenza Escobar, ${ }^{58}$ Garcerán de Vall ${ }^{59}$ y Álvarez Tabío, ${ }^{60}$ que fueron referentes también en el debate jurisprudencial cubano.

El triunfo de la Revolución cubana en 1959 condujo a una transformación institucional de gran complejidad que afectó las bases jurídicas del nuevo Estado socialista, consagradas definitivamente en el año 1976 luego de un largo periodo de provisionalidad constitucional. Las concepciones dominantes hasta entonces en materia de comprensión y aplicación de las fuentes del derecho cedieron paso a otras formas de interpretar este fenómeno, bajo la perspectiva del legalismo.

Con la promulgación de la Ley 59, Código Civil de la República de Cuba, el 16 de julio de 1987 se suprimió la regulación de las fuentes establecida al amparo de la antigua legislación civil española. Este hecho fue calificado por el profesor Pérez Gallardo como uno de los "extremos más endebles" de la reforma ${ }^{61}$ que, entre otras consecuencias, ha condicionado la determinación de las fuentes del derecho interno en cierta medida al "resultado de la especulación doctrinal de diferentes autores, sin asentamiento real en el derecho positivo vigente". ${ }^{2}$

Desde mediados de la década de los noventa, y luego de una etapa caracterizada por el retorno al legalismo bajo la influencia de las ideas provenientes del extinto campo socialista y la proyección política interna predominante en los primeros

51 Diego Vicente Tejera, Estado de la legislación cubana y de la influencia que ejerzan en ella la de España y la de otros países, Madrid, Reus S. A., 1925.

52 Pablo Desvernine y Galdós, Estudios fundamentales de derecho, La Habana, Librería Atenea, 1928, pp. 316 y ss. En el prólogo de Rafael Montoro, notas de interés en pp. VI y ss.

53 Mario Aramburo, Doctrinas jurídicas, La Habana, Imprenta "Cuba Intelectual”, 1916, pp. 35 y ss.; Filosofia del derecho, Nueva York, Instituto de las Españas, s. f., segunda parte; Teorías pragmáticas (ensayos de filosofia y ciencia jurídica), Madrid, Renacimiento, s. f., pp. 235 y ss.; Elementos de derecho civil, La Habana, Imprenta "El siglo XX", 1927, pp. 19 y ss.

54 Antonio SÁnchez de Bustamante y Montoro, La jurisprudencia en la jerarquía de las fuentes del derecho positivo cubano, 2 ed., La Habana, Jesús Montero Editor, 1937, pp. 7 y ss.

55 Antonio Sánchez de Bustamante y SiRvén, Proyecto de código civil de Cuba, La Habana, Editor Carrasa, 1940, p. 9.

56 Guillermo De Montagú, El juez ante la norma injusta y otros estudios, La Habana, Lex, 1944, pp. 18 y ss.

57 E. Fernández Camus, Filosofía jurídica contemporánea, La Habana, Jesús Montero Editor, 1932, capítulo V; Filosofia jurídica. Orientaciones fundamentales, Universidad de La Habana, 1948, capítulo X.

58 Pedro F. EnTenza Escobar, La norma jurídica civil (Estudio del artículo 6 del Código Civil), La Habana, J. Cebrian Editor, 1957, passim.

59 Julio Garcerán de VAll, El Juez, La Habana, Editorial Librería Martí, 1957, pp. 162 y ss.

60 Fernando Álvarez Tabío, “Tesis”, en AA. VV., Legalidad y justicia, La Habana, Editorial Biblioteca Jurídica de Autores Cubanos y Extranjeros, vol. CL, Jesús Montero Editor, 1952, pp. 29, 36,37; El recurso de inconstitucionalidad, La Habana, Editorial Librería Martí, 1960, pp. 18 y ss.

61 Leonardo B. Pérez Gallardo, "Tras la huella del legislador del Código Civil de los cubanos", en Leonardo B. Pérez Gallardo et al., Estudios de derecho civil cubano, Madrid, Consejo General del Notariado, 2002, p. 276.

62 Juan Mendoza Díaz et al., Lecciones de derecho procesal civil, op. cit., p. 10. 
años de la Revolución en el poder, se ha producido un importante giro en torno al estudio de las fuentes, que ha introducido una perspectiva más plural e incluyente, con desmarques puntuales respecto al tradicionalismo concentrado en el papel casi exclusivo de la ley como fuente del derecho en Cuba.

Varias de las tesis mencionadas en la parte introductoria realizan aportes sustanciales a este importante tópico. ${ }^{63}$ Sin embargo, persisten dificultades conceptuales y normativas relacionadas, en este último caso, con carencias de sistematización y reconocimiento expreso de las fuentes, que afectan al derecho interno de forma general y de modo particular a la jurisprudencia.

Respecto a la fuente objeto de estudio se realizó un examen de las principales etapas de su desarrollo histórico, para concretar la caracterización del debate en Cuba con base en la proyección doctrinal, normativa y las tendencias en la actividad judicial.

Esta evolución estuvo ligada a las transformaciones jurídicas que en la época colonial tuvieron como centro a España, especialmente en materia procesal y de organización de la administración de justicia; a la ampliación del interés sobre la cuestión jurisprudencial durante la primera mitad el siglo XX, matizada por la actuación del Tribunal Supremo de Justicia, y el rol de la doctrina legal y de otras instituciones jurídicas que coadyuvaron a la función creadora de los tribunales, con importantes autores patrios que se destacaron en el discurso teórico; ${ }^{64}$ a la decadencia y posterior eliminación, en la década de los setenta, del denominado sistema de jurisprudencia y el progresivo rescate del interés por la materia en las últimas dos décadas, a partir de aportes contenidos en investigaciones a distintos niveles, publicaciones periódicas y otras contribuciones teóricas que definen el estado actual del tema tratado, conforme se ha explicado en la introducción de la presente contribución.

La caracterización del debate sobre la jurisprudencia en Cuba pudiera entonces resumirse en las siguientes notas: i) la fecundidad de la discusión doctrinal y aportación práctica de la función judicial, especialmente durante la primera mitad del siglo XX; ii) la identificación de la jurisprudencia como doctrina legal; iii) la publicación sistemática de compendios de jurisprudencia en distintas materias; iv) las contradicciones en torno al carácter de la jurisprudencia dentro del sistema de fuentes y su validez formal o factual; v) el condicionamiento político de la jurisprudencia como fuente; vi) la ruptura de la cultura jurisprudencial frente al legalismo implantado en el proceso de transformaciones institucionales durante el periodo revolucionario.

63 Es preciso recordar en esta nota las tesis doctorales, antes citadas, de Prieto Valdés (2002), Mondelo García (2003), Pachot Zambrana (2007), Ferrari Yaunner (2010) y Pérez Carrillo (2013), que desde diferentes ángulos han aportado al cambio de perspectiva analítica sobre el fenómeno de las fuentes en Cuba.

64 Entre estos del Cueto, De Montagú, Bustamante y Montoro, Bustamante y Sirvén, Álvarez Tabío. 
El retorno a un sistema de validez formal de la jurisprudencia en Cuba estaría justificado ahora a partir de: i) el carácter democrático y popular de la función judicial cubana; ii) las limitaciones presentes en el proceso legislativo interno; iii) las exigencias de seguridad jurídica; iv) la necesaria sistematización del derecho; v) la inexistencia de una prohibición expresa de reconocimiento de esta fuente y, vi) el requerimiento de ampliar las vías de control de las actuaciones judiciales. Correlativamente, la dimensión funcional de la jurisprudencia y la constante búsqueda de medios complementarios para la materialización de la justicia ofrecen respuestas claves a cada uno de estos aspectos.

Lo anterior está complementado con el análisis de tendencias en opiniones de jueces y expertos que se desempeñan en la administración de justicia, cuyo muestreo probabilístico arroja criterios mayoritariamente favorables en relación con las condiciones propuestas para la validez formal de la jurisprudencia.

Los aspectos analizados permiten reafirmar que la problemática principal en torno a la jurisprudencia como fuente del derecho cubano está relacionada con la validez formal, que deriva de la contradicción actual entre la tendencia al reconocimiento fáctico, con énfasis en la práctica judicial, frente a la omisión normativa de su regulación dentro de las fuentes del ordenamiento jurídico interno.

En pos de la solución de esta problemática, la seguridad juridica y el perfeccionamiento de la función judicial, fueron propuestas las siguientes condiciones para la validez formal de la jurisprudencia en el derecho cubano, hecho que coadyuvaria a su adecuada identificación y obligatoriedad:

a) La jurisprudencia se establece por el tribunal de mayor jerarquía del sistema judicial en Cuba: el TSP.

Condición que parte de la tendencia al reconocimiento de los órganos judiciales superiores como los únicos facultados para formar jurisprudencia y establecer las reglas para su obligatoriedad. ${ }^{65}$

65 En esta dirección, la posible incidencia de una "jurisprudencia menor" aludida en algunos criterios de expertos en Cuba se agota en la facultad de confirmación que tiene el tribunal de más alta jerarquía en el sistema judicial. El problema de asimilar dicha categoría depende de una concepción amplia de jurisprudencia, es decir, jurisprudencia como toda actividad de los tribunales, que no es la que prevalece en este análisis. Lo dicho no ignora la importancia de los criterios sustentados por los jueces en salas de tribunales inferiores, fundamentalmente en los provinciales, en la construcción y consolidación posterior de patrones decisionales o líneas jurisprudenciales en el Tribunal Supremo Popular, que son extendidos al resto de la organización judicial. Admitir aquel tipo de jurisprudencia requiere un grado de perfeccionamiento del sistema de validez formal de esta fuente que debe transcurrir, en primer plano, por la admisibilidad del mismo y su puesta en práctica desde el TSP, y luego requiere una sólida preparación de los jueces en todas las instancias. Este enfoque toma en cuenta la realidad cubana, pues es cierto que a partir de los efectos antes comentados de la globalización jurídica y la expansión de la jurisprudencia creada por órganos supranacionales o regionales, buena parte de los sistemas judiciales asimilan criterios vinculantes que técnicamente no son producidos por las cortes supremas nacionales y que impactan, a su vez, tanto en la actividad de estas como en toda la estructura del sistema judicial. 
b) A partir de la fundamentación (ratio decidendi) de las sentencias dictadas en salas del TSP, con tendencia a su reiteración.

Esta es la manera más adecuada de identificar la jurisprudencia, que en Cuba tendria especial trascendencia pues coadyuvaría a delimitar la validez de esta fuente en el ámbito puramente jurisdiccional, y no como resultado de otros instrumentos normativos adoptados en los marcos de la administración del sistema judicial (v. gr., las disposiciones del CGTSP).

c) Que contienen patrones de decisión como respuestas jurídicas ante la inexistencia o insuficiencia de la norma aplicable al caso.

La jurisprudencia, en su carácter complementario, contribuye a resolver situaciones jurídicas frente a problemas de relevancia (ausencia normativa) o interpretación (insuficiencia de la norma). Este es un limite impuesto al arbitrio judicial y causa de justificación del reconocimiento de esta fuente.

d) Los patrones de decisión conformadores de jurisprudencia se forman mediante la colegiación y el consenso en las salas del TSP.

Condición que refuerza el papel de esta estructura en la determinación de los criterios jurisprudenciales obligatorios en las salas del TSP, logrados a base de colegiación y consenso, que aportan al carácter democrático y popular ínsito en la toma de decisiones que luego se expresan en las resoluciones judiciales.

e) Los patrones de decisión conformadores de jurisprudencia deben ser adecuadamente señalados y publicados.

Requisito que tributa directamente a la certeza del uso y la validez de la jurisprudencia como fuente, en donde es trascedente el conocimiento de la orientación de decisión del TSP no solo para los jueces, sino además para el resto de los operadores jurídicos y ciudadanos en general. Un medio para la materialización de este propósito puede ser el actual Boletín del Tribunal Supremo Popular.

f) Cambio jurisprudencial, debidamente argumentado, en virtud de una transformación de las circunstancias.

La determinación de esta condición procura evitar el estancamiento y la petrificación del razonamiento judicial. El cambio jurisprudencial es esencial, pero debe ir acompañado de una adecuada argumentación. De igual forma, ha de estar condicionado a la transformación esencial de las circunstancias que sustentaron la fundamentación jurídica precedente ${ }^{66}$ y la aparición de situaciones directamente relacionadas con la búsqueda de la justicia, la protección de los derechos e intereses ciudadanos o la materialización de los principios de igualdad y equidad procesal, entre otros. ${ }^{67}$

66 Este cambio de circunstancias incluiría las modificaciones normativas por cuyo efecto dejen de tener validez los criterios jurisprudenciales sentados por el TSP en casos previos donde no existía norma o esta era insuficiente.

67 La posición definida en el presente estudio es la de considerar el cambio jurisprudencial bajo los presupuestos descritos, sin necesidad de atar al órgano facultado para establecer jurisprudencia a 
g) Carácter vinculante de la jurisprudencia, complementado mediante el control casacional.

El reconocimiento de la validez formal de la jurisprudencia implica el de su carácter vinculante, es decir, obligatorio. El cumplimiento de esta condición debe ir complementado con la existencia de mecanismos de disciplina jurisprudencial, que en el contexto jurídico cubano actual apuntan hacia el recurso de casación. No obstante, esta propuesta no excluye la posible instrumentación a futuro de otras vías de tutela judicial en sede constitucional.

h) Reconocimiento constitucional.

La plena validez formal de la jurisprudencia depende de su reconocimiento normativo expreso, el cual debe materializarse, como criterio defendido por los autores, en la Constitución. El carácter fundamental, de fuente de fuentes y parte de la regla de reconocimiento adjudicado a la Constitución constituyen razones que justifican esta proposición, en aras también de contribuir a la sistematización del derecho interno a partir de la necesaria formación de un núcleo constitucionalizado de fuentes.

\section{CONCLUSIONES}

En el Derecho continental, desde la perspectiva antitradicionalista, el legalismo cede espacio a una concepción plural e incluyente de las fuentes, entre las cuales la jurisprudencia ha ocupado progresivamente centralidad en el debate doctrinal y a través de su reconocimiento normativo en varios ordenamientos jurídicos.

En la evolución histórico-conceptual de este último instituto han influido diversas contradicciones teóricas y factores políticos e ideológicos; esta fuente ha sido identificada generalmente en la solución contenida en la ratio decidendi de sentencias de los órganos judiciales superiores, con tendencia a la reiteración, y obligatorias ante ausencia o insuficiencia de la norma aplicable al caso; en la reiteración de fallos; en las resoluciones de jurisdicciones extraordinarias o específicas; en sentencias de casación que contienen soluciones jurídicas novedosas, y a partir de diferentes modalidades de interpretación en el ámbito judicial.

un número determinado de decisiones previas sobre el mismo asunto. En algunos modelos de referencia, como el mexicano, se habla de "jurisprudencia por reiteración" (art. 107-II constitucional; Acuerdo 5/2003 del Pleno de la Suprema Corte de Justicia de la Nación, entre otras disposiciones) o del desarrollo de un "sistema de precedentes jurisprudenciales fundamentado en los fallos de triple reiteración”, tal cual establece la Constitución ecuatoriana en su artículo 184.2, como parte de las funciones de la Corte Nacional de Justicia (que es, curiosamente, diferenciado respecto al precedente constitucional, según lo estableció en su momento la Resolución Administrativa 0004-10-AD-CC, del Pleno de la Corte Constitucional, punto 4 de las Directrices generales para la elaboración de precedentes constitucionales obligatorios). Respetando la naturaleza y el alcance de estas modalidades de formación jurisprudencial (a veces no exclusivas en estos propios ordenamientos), se considera con ello la introducción de ciertas rigideces, en lugar de la flexibilidad demandada y relativamente resuelta a partir de la posibilidad de admitir el cambio jurisprudencial condicionado y razonado, pero no silogísticamente sujeto a un número de fallos previos. 
La validez formal de las fuentes se predica del cumplimiento de determinados requisitos o condiciones de forma y procedimiento para su producción, lo que asegura para el operador jurídico y el ciudadano un mayor grado de certeza en la identificación y predictibilidad de los resultados en el uso de dichas fuentes. El carácter de fuente formal atribuido a la jurisprudencia deriva de la observancia de estas condiciones.

El debate cubano sobre la jurisprudencia como fuente, en distintos momentos históricos, ha estado caracterizado por: la fecundidad de la discusión doctrinal y aportación práctica de la función judicial, principalmente en la primera mitad del siglo XX; la identificación de la jurisprudencia con la doctrina legal; la necesaria publicación de compendios jurisprudenciales como guias prácticas y de estudio; las contradicciones en la determinación del carácter de esta fuente bajo condicionamientos políticos, y la ruptura de la cultura jurisprudencial frente al legalismo implantado en el periodo revolucionario que, junto a la influencia de las concepciones jurídicas del extinto campo socialista y la postura política prevaleciente contraria a la intervención de la función judicial en la creación del derecho, llevaron a la proscripción del sistema de jurisprudencia en los años setenta del pasado siglo.

En las últimas dos décadas, la doctrina y la práctica judicial cubana han puesto de relieve la utilidad de la jurisprudencia, y su posible reconocimiento en el ordenamiento jurídico se encuentra justificado por el carácter democrático y popular de la función judicial, las limitaciones presentes en el proceso legislativo interno, las exigencias de seguridad jurídica, la sistematización del derecho, la inexistencia de prohibición expresa de reconocimiento de esta fuente, la ampliación de las vías de control de las actuaciones judiciales, las diversas funciones de la jurisprudencia en el ordenamiento jurídico y la necesidad de contar con medios complementarios para la materialización de la justicia.

La validez formal de la jurisprudencia en el ordenamiento jurídico cubano derivaría del cumplimiento de condiciones de forma y procedimiento, y contribuiría a la solución de las contradicciones existentes entre su uso práctico y la ausencia de reconocimiento normativo. Estas condiciones son: que sea establecida por el TSP a partir de la fundamentación (ratio decidendi) de las sentencias dictadas en sus salas, con tendencia a la reiteración; que aquellas sentencias contengan patrones de decisión como respuestas jurídicas ante la inexistencia o las insuficiencias de la norma; patrones de decisión formados mediante la colegiación y el consenso, adecuadamente señalados y publicados; que exista posibilidad de cambio jurisprudencial, debidamente argumentado; que el carácter vinculante de esta fuente esté complementado con el control casacional, y que sea reconocida constitucionalmente.

La determinación del carácter de fuente formal de la jurisprudencia presupone necesarias modificaciones legislativas en materia procesal y en la administración de justicia, previas, paralelas o posteriores al proceso de reforma constitucional, que pudieran abrir un capitulo inédito en el reconocimiento normativo de las fuentes del derecho cubano. 


\section{REFERENCIAS}

AA.VV., "Investidura de los jueces del Tribunal Supremo Popular y de los tribunales provinciales", en Revista cubana de derecho 21 (2013) pp. 83-113. Recueprado de http://www.tsp.gob.cu/sites/default/files/libro/documento/7-sistema_judicial_cubano2017.pdf

Aarnio, Aulius, Essays on the Doctrinal Study of Law, Dordrecht, SpringerScience+Business Media-BV, 2011.

Aguirre Alonso, Raisa M., La jurisprudencia como fuente del Derecho en Cuba. Una mirada desde la actuación de las salas de lo Civil y de lo Administrativo. Tesis en opción al título académico de Máster en Derecho Constitucional y Administrativo, La Habana, 2013.

Álvarez Tabío, Fernando, “Tesis”, en AA. VV., Legalidad y justicia, La Habana, Editorial Biblioteca Jurídica de Autores Cubanos y Extranjeros, vol. CL, Jesús Montero Editor, 1952.

Álvarez TABío, Fernando, El recurso de inconstitucionalidad, La Habana, Editorial Librería Martí, 1960.

Aramburo, Mario, Doctrinas jurídicas, La Habana, Imprenta “Cuba Intelectual”, 1916.

ArAmburo, Mario, Elementos de derecho civil, La Habana, Imprenta "El siglo XX”, 1927.

Aramburo, Mario, Filosofia del derecho, Nueva York, Instituto de las Españas, s. f., segunda parte; Teorías pragmáticas (ensayos de filosofia y ciencia juridica), Madrid, Editorial Renacimiento, s. f.

Atienza, Manuel y Juan Ruiz Manero, "Seis acotaciones preliminares para una teoría de la validez jurídica”, en Doxa. Cuadernos de filosofia del derecho 23 (2003), pp. 719-735. DOI: 10.14198/DOXA2003.26.28

Bernal Cano, Natalia, "El poder creador del juez en la combinación o mezcla de los procedimientos constitucionales”, en Estudios Socio-Juridicos 12 (2010), pp. 11-34. Recuperado de https://revistas.urosario.edu.co/index.php/sociojuridicos/article/view/1182

Calvo Vidal, Félix, Lajurisprudencia, ¿fuente del derecho?, Valladolid, Lex Nova, 1992.

CAÑIZAREs, Diego Fernando, Teoría del Estado, La Habana, Editorial Pueblo y Educación, 1979.

Comisiones de Estudios Juridicos. Secretariado, ¿Cómo debemos organizar el nuevo sistema judicial?, La Habana, 1971.

Correas, Oscar, Teoría del derecho, México, Fontamara, 2004.

Cuenca Gómez, Patricia, "Sobre la complejidad de la teoria jurídica de la validez en Principia iuris". Conferencia dictada en el Primer Encuentro de Jóvenes Investigadores de la Sociedad Española de Filosofia Jurídica y Politica: neoconstitucionalismo en tiempos de postdemocracia, Universitat de València, 25 de abril 2012. 
Cutié Mustelier, Danelia, El sistema de garantias de los derechos humanos en Cuba. Tesis en opción al grado científico de Doctor en Ciencias Jurídicas, Universidad de Oriente, Santiago de Cuba, 1999.

DAVID, René y C. JAUFFRET-SPINOSI, Los grandes sistemas juridicos contemporáneos (trad. de J. SÁnchez Cordero), México, UNAM-Centro Mexicano de Derecho Uniforme-Facultad Libre de Derecho de Monterrey, 2010.

De Montagú, Guillermo, El juez ante la norma injusta y otros estudios, La Habana, Lex, 1944.

De Silva Gutiérrez, Gustavo, "La norma válida. Análisis sobre la validez de las normas jurídicas”, en Revista de la Facultad de Derecho de México LIX (252) (2009), pp. 117-132. DOI: 10.22201/fder.24488933e.2009.252.46513

Del ÁGuila, Rafael, La senda del mal, politica y razón de Estado, Madrid, Taurus, 2000.

Del Cueto, José A., Discurso leído en la solemne apertura de los tribunales el 2 de septiembre de 1918, La Habana, Librería e Imprenta "La Moderna Poesía”, 1918.

Desvernine y Galdós, Pablo, Estudios fundamentales de derecho, La Habana, Librería Atenea, 1928.

Díaz GonzÁlez, G. M., "Las oscilaciones del Tribunal Constitucional en su doctrina sobre el principio de seguridad jurídica”, en Revista general de derecho administrativo 32 (2013), pp. 1-34. Recuperado de https://www.iustel.com/ v2/revistas/detalle_revista.asp?id_noticia $=412963 \& d=1$

DuJARRIC HART, Rafael E., La jurisprudencia en el sistema de fuentes del derecho civil en Cuba. Proyecto de tesis doctoral (no concluido), Universidad de La Habana, 2008.

Entenza Escobar, Pedro F., La norma jurídica civil (Estudio del artículo 6 del Código Civil), La Habana, J. Cebrian Editor, 1957.

Fernández Bulté, Julio, Teoría del Estado y del derecho, t. 2, La Habana, Editorial Félix Varela, 2004.

Fernández Camus, E., Filosofia jurídica contemporánea, La Habana, Jesús Montero Editor, 1932.

Fernández Camus, E., Filosofia jurídica. Orientaciones fundamentales, Universidad de La Habana, 1948.

FerRari Yaunner, Majela, Los principios de legalidad y seguridad jurídica como fundamentos del proceso de integración del derecho para colmar las lagunas de la ley en Cuba. Tesis en opción al grado científico de Doctor en Ciencias Jurídicas, Universidad de La Habana, 2010.

GarCerán de VAll, Julio, El juez, La Habana, Editorial Librería Martí, 1957.

Garcini Guerra, Héctor, Derecho administrativo, La Habana, Editorial Pueblo y Educación, 1986. 
Garzón López, Pedro, "Pluralismo jurídico", en Eunomia. Revista en cultura de la legalidad 5 (2013-2014), pp. 186-193. Recuperado de https://e-revistas.uc3m. es/index.php/EUNOM/article/view/2178/

GÉnY, François, Método de interpretación y fuentes en Derecho Privado positivo, Madrid, Reus, 1925.

GonZÁlez JÁcome, Jorge, "El problema de las fuentes del derecho: una perspectiva desde la argumentación jurídica”, en Vniversitas 112 (2006), pp. 265-293. Recuperado de https://revistas.javeriana.edu.co/index.php/vnijuri/article/ view/ 14650

GonzÁlez MenÉndez, Cenia, La jurisprudencia como fuente formal del derecho penal cubano. Su utilidad práctica. Tesis en opción al título de Especialista en Derecho Penal, Sancti Spíritus, 2014.

Grossi, Paolo, De la codificación a la globalización del derecho, Navarra, AranzadiThomson Reuters, 2010.

Hart, Herbert L. A., Post scriptum al concepto del derecho, México, UNAM, trad. de Rolando Tamayo y Salmorán, 2000.

Huerta Ochoa, Carla, Conflictos normativos, México, UNAM, 2003.

Huerta OchoA, Carla, "Fuentes, validez y aplicabilidad de las normas", en E. CÁceRes, I. Flores, J. Saldaña y E. Villanueva (coords.), Problemas contemporáneos de la filosofia del derecho, México, UNAM, 2005.

IzDEBSKI, Hubert, "Les sources du droit dans les pays socialistes européens (histoire, théorie, pratique)", en Revue internationale de droit comparé 38 (1986), pp. 7-56. DOI: $10.3406 /$ ridc. 1986.2356

ItURRALde Sesma, Victoria, "Reflexiones sobre los conceptos de validez y existencia de las normas jurídicas”, en Doxa. Cuadernos de filosofia del derecho 31 (2008), pp. 157-176.

Jawitsch, L. S., Teoría general del derecho, La Habana, Ciencias Sociales, 1988.

López Medina, Diego E., El derecho de los jueces, Bogotá, Legis, 2011.

López Medina, Diego E., "Tres caminos históricos en la formación de la jurisprudencia en América Latina: recepción y vicisitudes del concepto de "doctrina legal' en la región”, en A. González y J. Del Río (comps.), Discusión jurídica contemporánea desde Michoacán, México, Tribunal Electoral del Estado de Michoacán, 2011.

López VILAS, Ramón, La jurisprudencia y su función complementaria del ordenamiento jurídico, Madrid, Civitas, 2002.

LudER, İtalo, “Concepto, función y técnica de la jurisprudencia”, en Revista Jurídica Argentina La Ley 37 (1945), pp. 901-911.

Málein, N., La legislación civil y la defensa de los derechos personales en la URSS, Moscú, Editorial Progreso, 1985. 
Mánov, A. et al., Teoría marxista del Estado y del derecho, Ciudad de La Habana, Editorial de Ciencias Sociales, 1981.

MARINON, Luiz G., "El precedente en la dimensión de la seguridad jurídica", en Ius et Praxis 18 (2012), pp. 249-266. Recuperado de http://www.revistaiepraxis. $\mathrm{cl} /$ index.php/iepraxis/article/view/69

Mariño Castellanos, Ángel, El control constitucional en Cuba. Tesis en opción al grado científico de Doctor en Ciencias Jurídicas, Universidad de Oriente, Santiago de Cuba, 1995.

Matilla Correa, Andry, "Comentarios sobre las fuentes del Derecho Administrativo cubano (excepto el reglamento)", en Armando CASTANedo ABAy et al., Temas de derecho administrativo cubano, La Habana, Editorial Félix Varela, 2006, pp. 33-219.

Mendoza Díaz, Juan et al., Lecciones de derecho procesal civil, La Habana, Editorial Félix Varela, 2001.

Millard, Eric, Théorie Générale du Droit, Paris, Dalloz, 2006.

Moliner TAmborero, G., "Las garantías de seguridad jurídica en las sentencias de casación”, en Actualidad jurídica 35 (2013), pp. 7-24. Recuperado de https://librosrevistas-derechuelos/vid/garanta-seguridad-jura-dica-sentencias-511781018

Mondelo García, Walter, El orden jurídico, la Constitución y la regla de reconocimiento. Tesis en opción al grado científico de Doctor en Ciencias Jurídicas, Universidad de Oriente, Santiago de Cuba, 2007.

ORDóñEz Solis, David, Jueces, derecho y politica. Los poderes del juez en una sociedad democrática, Pamplona, Aranzadi, 2004.

Pachot Zambrana, Karel, El derecho al deporte, la Constitución y las normas de ordenación del deporte en Cuba. Tesis en opción al grado científico de Doctor en Ciencias Jurídicas, Universidad de Oriente, Santiago de Cuba, 2007.

PÉRez CARrillo, Juan R., Presupuestos teóricos para el reconocimiento normativo de las fuentes formales legisladas del Derecho Agrario en Cuba. Tesis en opción al grado científico de Doctor en Ciencias Jurídicas, Universidad de Oriente, Santiago de Cuba, 2013.

Pérez Gallardo, Leonardo B., "Tras la huella del legislador del Código Civil de los cubanos”, en Leonardo B. PÉrez Gallardo et al., Estudios de derecho civil cubano, Consejo General del Notariado, Madrid, 2002, pp. 247-280.

Pérez LuÑo, Antonio Enrique, "Seguridad jurídica y sistema cautelar", en Doxa Cuadernos de filosofia del derecho 7 (1990), pp. 327-341. Recuperado de https:// rua.ua.es/dspace/bitstream/10045/10828/1/Doxa7_12.pdf

170 PÉrez LuÑo, Antonio Enrique, El desbordamiento de las fuentes del derecho, Sevilla, Real Academia Sevillana de Legislación y Jurisprudencia, 1993. 
Pérez Royo, Javier, Las fuentes del derecho, 5 ed., Madrid, Tecnos, 2012.

PRIETo VAldÉs, Martha, El derecho, la Constitución y su interpretación. Tesis en opción al grado científico de Doctor en Ciencias Jurídicas, Universidad de La Habana, 2002.

Puig Brutau, José, La jurisprudencia como fuente del derecho, 2 ed., Barcelona, Bosch, 2006.

Raz, Joseph, La autoridad del derecho. Ensayos sobre derecho y moral, México, UNAM, trad. de Rolando Tamayo y Salmorán, 1985.

RAz, Joseph, El concepto de sistema jurídico. Una introducción a la teoría del sistema jurídico, UNAM, México, trad. de Rolando Tamayo y Salmorán, 1986.

Ródenas Calatayud, Ángeles, "Validez formal y validez sustantiva. El encaje de la competencia material”, en Doxa. Cuadernos de filosofia del derecho 30 (2007), pp. 543-559. DOI: 10.14198/DOXA2007.30.47

Rodríguez Sánchez, Ciro Félix y R. M. Hernández, "La jurisprudencia como fuente complementaria del Derecho", en AA. VV., Memorias de la IV Conferencia Cientifica sobre el Derecho, Santiago de Cuba, Universidad de Oriente, 1997, pp. 39-44.

Sánchez de Bustamante y Antonio Montoro, La jurisprudencia en la jerarquía de las fuentes del derecho positivo cubano, 2 ed., La Habana, Jesús Montero Editor, 1937.

Sánchez de Bustamante y Antonio Sirvén, Proyecto de Código Civil de Cuba, La Habana, Editor Carrasa, 1940.

SÁnchez Rodríguez, Bárbara, La jurisprudencia: ¿método de interpretación o de creación en el derecho penal? Tesis en opción al título de Especialista en Derecho Penal, Santiago de Cuba, 2007.

Tamayo y Salmorán, Rolando, “Jurisprudencia y formulación judicial del Derecho (Principium)", en Isonomia 21 (2004), pp. 193-215. Recuperado de http://www. scielo.org.mx/scielo.php?script=sci_arttext\&pid=S1405-02182004000200007

TARUfFo, Michele, "La jurisprudencia entre casuística y uniformidad", en Revista de derecho (Valdivia) XXVII (2014), pp. 9-20. Recuperado de https://scielo. conicyt.cl/scielo.php?script=sci_arttext\&pid=S0718-09502014000200001

TEJERA, Diego Vicente, Estado de la legislación cubana y de la influencia que ejerzan en ella la de España y la de otros paises, Madrid, Reus, 1925.

VAllet de Goytisolo, Juan B., "El razonamiento judicial", en Anales de la Real Academia de Jurisprudencia y Legislación 39 (2009), pp. 17-32.

Vilajosana, Josep M., Identificación y justificación del derecho, Madrid, Marcial Pons, 2007. 
WRÓBLEWSKI, J., "Validitá e struttura del sistema giuridico. Metateoria e teoria pura del diritto", en Letizia Gianformaggio (comp.), Sistemi normativi statici e dinamici, analisi di una tipología kelseniana, Turín, Giappichelli, 1991.

Wróblewski, J., The Judicial Application of Law, Dordrecht, SpringerScience+Business Media-BV, 1992.

ZACCARIA, Giuseppe, "La jurisprudencia como fuente de derecho: una perspectiva hermenéutica”, en Isonomía 32 (2010), pp. 93-117. Recuperado de http: / /www.scielo.org.mx/scielo.php?script=sci_abstract\&pid=S1405$02182010000100005 \& \operatorname{lng}=$ pt\&nrm=iso

ZAMBRAno, Pilar, "El rechazo del formalismo y las tesis de las fuentes sociales", pp. 8-9, recuperado de bibliohistorico.juridicas.unam.mx/libros/6/2690/5.pdf, fecha de consulta: 23 de abril de 2016.

Zenati, Frédéric, La jurisprudence, Paris, Dalloz-Sirey, 1991.

Zhidkov, O., V. Chirkin y Y. Yudin, Fundamentos de la teoría socialista del Estado y el derecho, Moscú, Editorial Progreso, 1980. 